\title{
A INTENSA MILITÂNCIA DE GRAMSCI: UMA ÊNFASE AOS ESCRITOS POLÍTICOS.
}

\author{
LA INTENSA MILITÁNCIA DE GRAMSCI: UNA ÊFASE A LAS ESCRITOS POLÍTICOS.
}

\section{THE INTENSE MILITANCE OF GRAMSCI: AN EMPHASIS TO POLITICAL WRITINGS.}

\author{
DOI: http://dx.doi.org/10.9771/gmed.v11i2.28686
}

Wanderson Pereira Lima ${ }^{1}$

\begin{abstract}
Resumo: Este estudo, fruto de uma pesquisa bibliográfica, tem o objetivo de apresentar mesmo que de maneira introdutória, a intensa militância de Gramsci no momento áureo de sua função como ativista político, sobretudo atuando com intuito de constituir a consciência unitária da classe trabalhadora - principalmente a união entre os operários do norte e os camponeses do sul - com vistas à revolução comunista na Itália, enfatizando seus Escritos Políticos I e II. Esse entusiasmo revolucionário de Gramsci entrou em ebulição entre os anos de 1910 e 1926 , período em que atuou como jornalista e que se consolidou como cidadão partidário nas lutas pelas causas proletárias. O Biênio Vermelho anos de 1919-1920 é destacado nesse estudo, devido a grande efervescência política italiana, destacando-se nesse contexto os Conselhos de Fábrica que por sinal era considerado por Gramsci e seus camaradas, forte instrumento visando à revolução. Pode-se concluir que esse ímpeto militante de Gramsci nasceu e cresceu com o próprio, e foi o acompanhando em toda sua vida, seja pela sua condição de homem sardo, seja pelas influências familiares, e/ou seja pela sua vida acadêmica e profissional em Turim, tornando-se notório finalizar expondo o sentimento de serenidade e orgulho de Gramsci por toda uma vida militante.
\end{abstract}

Palavras-chave: Gramsci, Militância política, Escritos Políticos.

Resumen: Este estudio, fruto de una investigación bibliográfica, tiene el objetivo de presentar incluso de manera introductoria, la intensa militancia de Gramsci en el momento áureo de su función como activista político, sobre todo actuando con el propósito de constituir la conciencia unitaria de la clase trabajadora, unión entre los obreros del norte y los campesinos del sur - con vistas a la revolución comunista en Italia, enfatizando sus Escritos Políticos I y II. Este entusiasmo revolucionario de Gramsci entró en ebullición entre los años 1910 y 1926 , período en que actuó como periodista y que se consolidó como ciudadano partidario en las luchas por las causas proletarias. El Bienio Rojo años de 1919-1920 es destacado en ese estudio, debido a la gran efervescencia política italiana, destacándose en ese contexto los Consejos de Fábrica que por cierto era considerado por Gramsci y sus camaradas, fuerte instrumento para la revolución. Se puede concluir que ese ímpetu militante de Gramsci nació y creció con el propio, y fue el acompañamiento en toda su vida, sea por su condición de hombre sardo, sea por las influencias familiares, y / o sea por su vida académica y profesional en Turim, haciéndose notorio finalizar exponiendo el sentimiento de serenidad y orgullo de Gramsci por toda una vida militante.

Palabras clave: Gramsci, Militancia política, Escritos Políticos.

Abstract: This study, the fruit of a bibliographical research, aims to present, even in an introductory way, the intense militancy of Gramsci at the golden age of his role as a political activist, especially in order to constitute the unitary consciousness of the working class - union between the workers of the north and the peasants of the South - with a view to the communist revolution in Italy, emphasizing Political Writings I and II. This revolutionary enthusiasm of Gramsci boiled between the years 1910 and 1926, when he acted as a journalist and consolidated as a party citizen in the struggles for proletarian causes. The Red Biennial years of 1919-1920 are highlighted in this study, due to the great Italian political effervescence, highlighting in this context the Factory Councils that by the way was considered by Gramsci and his comrades, a strong instrument aimed at the revolution. It can be concluded that this militant impetus of Gramsci was born and grew up with his own, and was accompanying him throughout his life, whether by his condition as a Sardinian man or by family influences, and / or by his academic and professional life in Turin, making it notorious to end by exposing Gramsci's sense of serenity and pride throughout a militant life.

Key words: Gramsci, Political militia, Political writings

\section{Introdução}


Ser comunista, votar o Partido Comunista significa afirmar a convicção na verdade deste programa, a disposição de lutar pela sua realização, enviando ao Parlamento homens que nada mais se propõem do que afirmar estes princípios, do que fortalecer o organismo que guia a parte melhor da classe operária no sentido de sua realização em todo o mundo. (Gramsci, 2004b, p.62).

Os anos de 1919 e 1920 no contexto político italiano são conhecidos como o biênio vermelho, pois é devido ao calor de uma mobilização intensa da sociedade que objetivava a tomada do poder pelas classes oprimidas e a implantação de um novo Estado - o Estado operário. Para tanto, era necessário de fato à unificação de toda a classe trabalhadora italiana, que por sinal era compreendida por uma minuciosa dualidade socioeconômica; os camponeses característicos da zona rural do sul e os operários advindos da zona urbana do norte.

O biênio vermelho é caracterizado também por um forte entusiasmo de Gramsci com as premissas revolucionárias. A organização, a homogeneização, a difusão dos interesses comunistas era uma preocupação fundamental para concretizar a revolução e a instauração do Estado proletário.

Para Gramsci os conselhos de fábricas eram verdadeiramente revolucionários, eram interpretados como uma importante engrenagem em busca da constituição de um Estado igualitário. Era necessário instruir a classe trabalhadora para que a mesma aos poucos fosse constituindo uma consciência de classe, constituindo um espírito de luta, portanto, com essas premissas nada melhor que um contato direto com os trabalhadores.

O objetivo deste estudo é destacar o entusiasmo militante de Gramsci no momento áureo de sua função como ativista político, sobretudo atuando com intuito de constituir a consciência unitária da classe trabalhadora com vistas à revolução comunista, enfatizando no presente estudo os Escritos Políticos I e II. Torna-se importante destacar que os textos que compõem esses escritos, são textos característicos que relatam à intensa militância ativista de Gramsci, compreendidos em 1910 e 1926 - sendo destacado nesse período o Biênio Vermelho e os Conselhos de Fábrica.

\section{A militância de Gramsci}

Antônio Gramsci nasceu no ano de 1981 em Ales região da Sardenha, quarto dos sete filhos de Francesco e Guiseppina Marcias. Desde criança tinha sérios problemas de saúde e também tinha uma deficiência física - era corcunda. Sua família não era de origem rica, porém não passavam por problemas de pobreza, contudo, após Francesco ser afastado do emprego e preso por infrações administrativas a família passa por sérias dificuldades de econômicas (GRAMSCI, 1999).

Desde muito jovem, Gramsci já se interessava por assuntos políticos, por forte influência da mãe e das irmãs tornou-se um grande estudioso e também pela influência de seu irmão Gennaro começou a ler a impressa socialista, com isso, aos poucos foi constituindo seu ímpeto revolucionário. A convivência com Gennaro (que mais tarde se tornaria secretario de seção do PSI) influenciou fortemente o jovem Antônio em sua formação e constituição como militante dedicado às causas políticas, principalmente pelas intenções de emancipação e reconhecimento das classes trabalhadoras. 
Devido à situação precária de seu lugar de origem - a Sardenha - e a exploração provocada pelas classes dominantes, às aspirações por justiça social provocava em Gramsci um sentimento de revolta contra os ricos e opressores. De acordo com Fiori (2015) a ideologia propagandista da burguesia ridicularizava os sardos e as comunidades localizadas na região sul da Itália, "os meridionais são biologicamente inferiores, semibárbaros ou bárbaros completos, por destino natural (p.93)".

Já como universitário se deparava com as lutas operárias, com as greves, e ficava impressionado com todo aquele movimento e sua organização, aquele entusiasmo dos operários manifestava em Gramsci um sentimento de que aquilo era coisa de outro mundo, de outra humanidade. Na segunda metade de 1913 as eleições movimentaram o contexto político italiano, pois era a primeira desde a extensão do sufrágio universal. $\mathrm{Na}$ Sardenha o fervor político estava a todo vapor, principalmente contra o protecionismo. Em meio a esse contexto, Gramsci consolidava sua adesão à propaganda antiprotecionismo, era a primeira vez que um jovem estudante sardo se aderia à batalha política (FIORI, 2015).

Nesse mesmo ano, ele entra para o Partido Socialista, iniciando de fato sua militância. Começa a ler "La Voce e L’Unitá" periódicos de renome dirigidos por Prezzolini e Salvemini (importantes intelectuais italianos). Põe-se ao lado dos grupos mais radicais de operários e estudantes; colabora com o "Il Grido del Popolo", semanário socialista e também passa a fazer parte da redação do Avanti. Daí em diante dedica-se a intensa atividade jornalística, ressaltando o movimento socialista e seus propósitos (GRAMSCI, 1999).

Em 1917 entra para a secretaria do partido socialista; 1919 cria com seus camaradas o fundamental jornal L’Ordine Nuovo; 1921 a criação do Partido Comunista; 1924 é eleito deputado; em 1926 é preso pela polícia fascista com outros deputados comunistas. Mesmo no cárcere, não abandona sua militância, nos primeiros anos organiza com alguns companheiros de prisão uma escola para os confinados, e em 1929 começa a redigir os famosos Cadernos do Cárcere (idem). Pode-se perceber que Gramsci se dedica verdadeiramente à militância política, o seu projeto de vida foi concretizado a favor da causa proletária, mesmo estando em situações remotas.

Voltemos agora a sua dedicada e intensa vida jornalística, que por sinal, em paralelo e em favor a sua militância, escreveu vários artigos objetivando mobilizar a classe trabalhadora e expor fortes críticas ao capitalismo italiano e seu governo. Uma de suas diversas críticas é endereçada ao modo de educação do Estado burguês;

Um proletário, ainda que inteligente, ainda que com todas as condições necessárias para tornar-se homem de cultura, é obrigado ou a desperdiçar suas qualidades em outra atividade, ou a tornar-se um obstinado, um autodidata, ou seja, com as devidas exceções, um meio homem, um homem que não pode dar tudo o que poderia dar casa tivesse se completado e fortalecido na disciplina da escola. A cultura é um privilégio. A escola é um privilégio. E não querermos que seja assim. Todos os jovens deveriam ser iguais diante da cultura (Gramsci, 2004a, p.74).

Com todo o desprezo exercido pela classe burguesa dominante para com os trabalhadores, os segundos são obrigados a ingressarem em escolas técnicas e profissionais, o que por sinal sofrem por falta de orçamente estatal, transformando-se em uma repetição das escolas clássicas, gerando uma má formação e uma mão de obra barata e automática para o empreguismo da burguesia, de acordo com Gramsci (2004a). Para ele, o proletariado necessita de uma escola que dê a possibilidade de a criança se tornar homem, adquirir 
critérios para o desenvolvimento do caráter, "uma escola de livre iniciativa, não uma escola de escravidão e de orientação mecânica” (p.75). Deixando claro que mesmo a escola profissional é capaz de transformar a criança em homem, "contanto que se trate de cultura educativa e não só informativa ou não só prática manual" (p.76).

Entretanto, para que seja possível realizar esse tipo de sistema educacional visado por Gramsci, era necessário à tomada de poder pela classe trabalhadora, era necessária a revolução por parte dos oprimidos e explorados, e a posteriori a implantação de um Estado operário, um Estado de ordem que verdadeiramente reconheça a classe trabalhadora.

Os socialistas não devem substituir uma ordem por outra. Devem instaurar a ordem em si. A máxima jurídica que eles querem realizar é: possibilidade de realização integral da própria personalidade bumana concedida a todos os cidadãos. Com a concretização dessa máxima, desaparecem todos os privilégios constituídos. Ela conduz ao máximo de liberdade com o mínimo de coerção. Pretende que a regra da vida e das tarefas seja a capacidade e a produtividade, fora de qualquer esquema tradicional. Que a riqueza não seja instrumento de escravidão, mas que, sendo de todos de modo impessoal, dê a cada um os meios para todo o bem-estar possível. Que a escola eduque os inteligentes, nasçam onde nascerem e deixe de ser o prêmio (Gramsci, 2004a, p.83).

Para a tomada de poder e instaurar o programa socialista é necessário tomar partido, lutar pelos seus interesses, entrar em combate contra aqueles que tanto exploram e oprimem a classe trabalhadora. É imprescindível compreender e organizar a luta de classes, pois somente os operários podem alcançar a sua liberdade.

Portanto, Gramsci (2004a) declarava sua insatisfação com aqueles que ele mesmo chama de os indiferentes. "Quem vive verdadeiramente não pode deixar de ser cidadão, e de tomar partido" (p.84). Os indiferentes eram aqueles que não tomavam partido, aqueles que não manifestavam sua indignação, que se dizem inertes as lutas de classe, aqueles que eram omissos aos debates que conduzem o rumo da sociedade. "Vivo, tomo partido. Por isso, odeio quem não se compromete, odeio os indiferentes" (p.86).

Em sua militância, o revolucionário comunista italiano em destaque neste estudo, era comprometido com as questões sociais, entrava de corpo e alma em sua saga operária. Convocando os jovens a se escreverem no movimento juvenil socialista, destacando a disciplina e a liberdade de seguir os preceitos revolucionários, visando evitar que os mesmos se tornem omissos perante a luta classista. Pois a propaganda socialista estimula o conhecimento, a ânsia pela sabedoria, estimula o indivíduo a se tornar um ser dentre o sistema orgânico livre, e que disciplina as classes trabalhadoras com vistas a reconhecer os seus interesses (GRAMSCI, 2004a).

O Estado proletário socialista existe potencialmente nas vidas sociais características da classe trabalhadora explorada, o intuito era manifestar essa energia oculta que está obscurecida pelo condicionamento opressor burguês, tal energia capaz de promover uma verdadeira democracia - a democracia operária - com efetivas forças para substituir o Estado burguês. O dever de organizar e articular o proletariado para a tomada de poder é preponderante, formalizando uma sociedade educada e capaz de manter a educação emancipadora (GRAMSCI, 2004a).

A fórmula "ditadura do proletariado" deve ser apenas uma fórmula, uma ocasião para dar vazar à fraseologia revolucionária. Quem quer o fim deve também querer os meios. 
A ditadura do proletariado é a instauração de um novo Estado, tipicamente proletário, no qual confluem as experiências institucionais da classe oprimida, no qual a vida social da classe operária e camponesa se torna sistema difundido e fortemente organizado. Este Estado não se improvisa: os comunistas bolcheviques russos trabalharam durante oito meses para divulgar e tornar concreta a palavra de ordem "todo o poder aos sovietes"; e os operários russos conheciam os sovietes desde 1905. Os comunistas italianos devem assimilar a experiência russa e economizar tempo e trabalho que a ela devem ser dedicados cada dia e cada ato (idem, p.249).

Citando a Revolução Russa como exemplo, Gramsci (2004a) dizia que uma revolução não é proletária pelo simples fato de ser realizado por proletários, é necessário uma mudança de costumes, de moral, de espírito; portanto foi isso que aconteceu na Rússia. Eles ignoraram o jacobinismo da revolução burguesa francesa, por isso Gramsci citava que o jacobinismo era um movimento que visava substituir um poder autoritário por outro, que beneficiavam o interesse de uma minoria dominante. Já a Revolução Russa ultrapassava essas perspectivas jacobinas, ela visava instaurar um Estado igualitário a todos; constituindo uma liberdade física, moral e espiritual.

Gramsci (2004a) criticava fortemente a visão “de Messias” que o jacobinismo tinha. Denunciava o caráter de abstração (bem, mal, luz, trevas) do sistema politico e social, que por sinal essa abstração escapava as formas concretas e históricas, como são as instituições econômicas. Para ele o caráter abstrativo “dissolve o sentimento da responsabilidade social, esvazia toda crítica, já que a crítica que ele propõe dirige sua investigação não para o concreto, mas para fantasmas flutuantes da mais evanescente contingência" (p.196).

Esse messianismo jacobino é pertencente à política do "se", que segundo Gramsci tinha muitos seguidores na Itália - inclusive, estão presentes alguns de seus companheiros do PSI: Gaetanno Salvemini, Angelo Tasca e Cláudio Treves. Repleto de abstrações e previsões, esse tipo de analisar o sistema político era considerado pelo nosso autor como aquele que se “exime do pensar e estudar" (idem, p.193).

A política do "se" consiste em não levar minimamente em contas as forças organizadas; em não dar nenhuma importância as responsabilidades legítimas, livremente aceitas quando se assume um poder; em negligenciar a investigação da função, dos modos em que se processa a atividade econômica e das consequências necessariamente determinadas por estes específicos modos nas relações culturais e de convivência. (...) Por causa dessa política do "se", com efeito, são negligenciadas as forças permanentemente ativas no desenvolvimento dos eventos humanos e que continuam a operar apesar de todos os belos discursos; ao contrário, fixa-se a atenção no passageiro, no ocasional, ou em uma energia livre que tem na realidade uma limitada importância (ibidem).

Percebe-se o notório desgosto que Gramsci tem em relação a tal política do "se" e principalmente ao jacobinismo que era fruto da revolução francesa e complementado na Itália pelo messianismo cultural, revestido por uma roupagem católica e protestante, fomentado pela fé na eficácia da discussão e da propaganda. Tornando-se assim presos as abstrações e ao modo genérico de observar a realidade, desprendendo-se da realidade concreta.

A questão de levar em consideração a historicidade das relações sociais, a organização das massas, a união entre operários do norte e camponeses do sul deve ser entendida como um verdadeiro propósito em constituição da revolução. Segundo Gramsci (2004a), o partido e as massas devem ser compreendidos 
como um só, "socialismo é organização, e organização não só política e econômica, mas também e, sobretudo de saber e vontade, obtida através da atividade cultural” (p.213).

A proposta de Pellegrino ${ }^{2}$ de criar uma Associação de Cultura - de cultura proletária - foi bem vista por Gramsci (2004a). Tal associação teria como função promover a discussão sobre assuntos voltados a vida integral do programa socialista, sua filosofia, sua moral, seus preceitos intelectuais, pois; "Falta ao povo italiano o espírito de solidariedade desinteressada, o amor pela livre discussão, o desejo de buscar a verdade com os meios unicamente humanos, tais como os fornecidos pela razão e pela inteligência” (p.125).

Portanto, constituir um pensamento livre no povo italiano era uma das premissas do programa socialista. De acordo com Gramsci (2004a) na medida em que os socialistas pensam livremente, de modo historicista, ressaltando os fatos sociais concretos e coletivos, próprios da contradição e suas possibilidades, podem vencer essas mesmas contradições, ampliando seus horizontes e concretizando novos objetivos.

Com essa ampliação das perspectivas dos operários, estimulando-os a pensar livremente se reconhecendo enquanto sujeitos históricos, sujeitos que podem se organizar e promover a revolução, porém uma revolução que visa à tomada de poder pela classe trabalhadora, em seus setores jurídicos, econômicos, culturais, educacionais etc. Uma revolução verdadeiramente proletária e comunista.

A revolução é proletária e comunista somente quando a liberação de forças produtivas proletárias e comunistas que se vinham elaborando no próprio seio da sociedade dominada pela classe capitalista; só é proletária e comunista na medida em que consegue favorecer e promover a expansão e a organização de forças proletárias e comunistas capazes de iniciar o trabalho paciente e metódico necessário para construir uma nova ordem nas relações de produção e de distribuição, uma ordem na qual se torne impossível a existência da sociedade dividida em classes e cujo desenvolvimento sistemático, por isso, tenda a coincidir com um processo de esgotamento do poder de Estado, de dissolução sistemática da organização política de defesa da classe proletária, que se dissolve como classe para se tornar humanidade (GRAMSCI, 2004a, p.377-378).

Em uma proposta de mudança da estrutura do modo de produção sobre o caráter revolucionário, era necessário à mobilização da classe trabalhadora, mediante os vários setores em que a mesma está inserida. Nessa prerrogativa, os conselhos de fábrica eram instrumentos importantes para a constituição da consciência de classe nos operários, sendo mobilizada por intelectuais orgânicos, que por sua vez recebiam um grandioso auxílio do programa L’Ordine Nuovo.

\section{Conselhos de fábrica}

Para Gramsci, o conselho de fábrica seria o principal alicerce para a formação de uma estrutura operária organizada, com o intuito da constituição de um Estado operário na Itália. Pois, com a falta de organização e sistematização da classe trabalhadora, os mesmos poderiam cair nas falácias jurídicas orquestradas pelo estado burguês tendo como sua principal ferramenta os sindicatos.

Gramsci (2004a) expõem severas críticas aos sindicatos, afirmando que "Num certo sentido, pode-se afirmar que esse tipo de organização é parte integrante da sociedade capitalista e tem uma função inerente ao regime de propriedade privada (p.287)". Devido ao seu caráter reformista, os sindicatos visam 
uma espécie de negociata com os capitalistas e não uma ruptura com os moldes opressivos de seu modo de produção.

Por sua vez, o conselho de fábrica é o reflexo revolucionário da classe trabalhadora, é aquele que representa os íntimos desejos socioeconômicos dos operários, é aquele que representa a voz dos explorados e oprimidos pelo sistema capitalista, é o caminho a se trilhar para fundamentar e construir a ditadura proletária.

A ditadura proletária pode se encarnar num tipo de organização que seja específico da atividade própria dos produtores e não dos assalariados escravos do capital. O conselho de fábrica é a célula primária desta organização. Dado que, no conselho, estão representados todos os ramos do trabalho, na proporção da contribuição que cada categoria profissional e cada ramo do trabalho dá à elaboração do objeto que a fábrica produz para a coletividade, esta instituição é de classe, é social. Sua razão de ser está no trabalho, na produção industrial, ou seja, num fato permanente e não mais no salário, na divisão de classes, isto é, num fato transitório, que se trata precisamente de superar (Gramsci, 2004a, p.288).

Pode-se perceber a importância do conselho de fábrica na perspectiva da homogeneidade da classe trabalhadora, ou seja, "o conselho de fábrica é o modelo do Estado proletário. Todos os problemas inerentes à organização do Estado proletário são inerentes à organização do conselho" (idem). Portanto, a unificação da classe trabalhadora na Itália - e consequentemente nos países capitalistas ocidentais - dependeriam da organização da mesma, e principalmente da consolidação de órgãos como o conselho de fábrica em prol da constituição da consciência de classe.

Com a consciência de classe - de classe trabalhadora - os operários e camponeses, poderiam tornar-se mais solidários uns aos outros, havendo uma colaboração entre os explorados em busca da superação das classes, visando uma sociedade verdadeiramente igualitária, livre das promiscuidades impostas pela ordem burguesa.

A existência do conselho dá aos operários a responsabilidade direta da produção, leva-os a melhorar seu trabalho, instaura uma disciplina consciente e voluntária, cria a mentalidade do produtor, do criador de história. Os operários levam para o sindicato esta nova consciência; e, além da simples atividade da luta de classe, o sindicato passa a se dedicar ao fundamental trabalho de imprimir uma nova configuração à vida econômica e de técnica profissional que é própria da civilização comunista. Neste sentido, os sindicatos - que são formados pelos operários melhores e mais conscientes - realizam o momento suprema da luta de classe e da ditadura do proletário: criam as condições objetivas nas quais as classes não mais podem existir nem renascer (Gramsci, 2004a, p.290).

Com isso, a solidariedade operária se torna no conselho, algo positivo, pois no momento da produção, os mesmos podem se observar como parte de um todo, de um conjunto de trabalhadores com os mesmos intuitos, com os mesmos interesses, fazendo parte de um sistema orgânico, sob um sistema homogêneo e compacto, desenvolvendo sua liberdade criadora de história (GRAMSCI, 2004a).

Com esse sentimento de solidariedade, a classe trabalhadora se fortalecia e poderia tomar aos poucos a direção das relações sociais do sistema econômico, pois segundo Gramsci (2004a), nenhuma sociedade existe sem os meios de produção historicamente determinado, e no contexto estrutural em que a Itália e os países ocidentais estavam vivendo, a única classe que se identificava com a fábrica era a trabalhadora. 
A classe trabalhadora é a senhora da sociedade porque domina a produção - ou seja, é a única que vive de fato com os meios produtivos, é a única que verdadeiramente os manuseia. Para Gramsci (2004a), quanto mais o trabalhador se especializa em uma ação profissional, mais se torna indispensável em relação ao seu companheiro, por meio disso, essa necessidade de ordem e coesão que é constituído na fábrica, poderá ser construída também fora dela, na sociedade. "Por essa sua originalidade, por essa sua específica concepção de mundo, o operário fabril, o proletário da grande indústria urbana é o campeão do comunismo (...)"(p.325).

No processo de adquirir consciência de sua força, de sua função no modo de produção, a classe trabalhadora poderia ampliar seus horizontes em relação à organização da sociedade, atingindo as grandes áreas, como: educação, a área jurídica, entre outras, visando um pensamento unitário (entre os trabalhadores) com perspectivas à revolução.

Ao construir este aparelho representativo, a classe operária efetua na realidade a expropriação da primeira máquina, do mais importante instrumento de produção: a classe operária, que se reencontrou, que adquiriu consciência de sua unidade orgânica e se contrapões agora, unitariamente, ao capitalismo. Deste modo, a classe operária afirma que o poder industrial, que a fonte do poder industrial deve retornar à fábrica; coloca novamente a fábrica, do ponto de vista operário, como forma na qual a classe operária se constitui como corpo orgânico determinado, como forma de um novo Estado, o Estado operário, como base de um novo sistema representativo, o sistema de conselhos. O Estado operário, por nascer com base numa configuração produtiva, cria com isso as condições do seu desenvolvimento, da sua dissolução como Estado, da sua incorporação orgânica a um sistema mundial, ou seja, a Internacional Comunista (idem, p.365-366).

Com a ambição de desenvolver a consciência de classe nos trabalhadores, formar um ímpeto crítico, um Estado unitário de caráter orgânico e operário, grandes personagens - Togliatti, Tasca e Terracine - juntamente com Gramsci fundaram o programa L'Ordine Nuovo (A Nova Ordem). Este era um jornal semanário de caráter verdadeiramente formativo da classe trabalhadora, ou seja, para eles era necessário bombardear a população com informações políticas.

De acordo com Gramsci (2004a), o que os uniam era o sentimento de paixão pela cultura proletária. As ideias de ambos os idealizadores do programa, eram algumas bem vistas outras fortemente criticadas por Gramsci, principalmente as perspectivas de Tasca, que eram taxadas de abstratas e desconexas da força concreta da realidade naquele presente momento. Todavia, o trabalho nunca parava, entre as primeiras publicações foram convidados a realizar cursos, palestras, círculos educativos em fábricas, e então aos poucos L'Ordine Nuovo de fato tornou-se o jornal dos conselhos de fábrica.

Gramsci (2004a) demonstra uma grande satisfação ao falar que os “operários amaram” o jornal, porque o mesmo representa suas paixões, suas vontades, seus descontentamentos, suas preocupações principalmente em relação à liberdade -, eles observavam L'Ordine Nuovo como a expressão da classe trabalhadora. Essa satisfação de Gramsci em citar o sentimento dos operários pelo jornal foi como a impressão de estar trilhando o caminho correto, pois, a concepção de L’Ordine Nuovo “estava organizada em torno de uma ideia, da ideia de liberdade (e, concretamente, no plano da criação histórica real, em torno da hipótese de uma ação autônoma revolucionária da classe operária)” (idem, p.406). 
A classe burguesa unificou territorialmente o povo italiano, cabe à classe operária unifica-los economicamente e espiritualmente, segundo Gramsci (2004b). Porém isso só pode ocorrer nos lugares em que o capitalismo estava mais desenvolvido na Itália, ou seja, nas regiões do norte - Turim, Milão, Bolonha.

Em especial, Turim de acordo com Gramsci (2004a) era a capital de um pequeno Estado que compreendia Piemonte, Ligúria e a Sardenha, no período antecessor a revolução burguesa na Itália, onde a mesma era predominantemente o centro da indústria e do comércio. Com isso Turim era uma cidade muito especial e fundamental para se concretizar os princípios da revolução;

Desde a unificação do reino da Itália e da transferência da capital para Roma, pareceu que Turim corria o perigo de perder sua importância. Mas a cidade superou rapidamente a crise econômica e tornou-se um dos centros industriais mais importantes da Itália. Pode-se dizer que a Itália tem três capitais: Roma, como centro administrativo do Estado burguês; Milão, como centro comercial e financeiro do país (todos os bancos, firmas comerciais e instituições financeiras se concentram em Milão); e, finalmente, Turim, como centro industrial, onde a produção industrial atingiu seu máximo grau de desenvolvimento. Com a transferência da capital para Roma, emigrou de Turim toda a pequena e média burguesia intelectual, que forneceu ao novo Estado burguês o pessoal administrativo necessário para seu funcionamento. Ao contrário, o desenvolvimento da grande indústria atraiu para Turim a nata da classe operária italiana. O processo de desenvolvimento desta cidade é, do ponto de vista da história italiana e da revolução proletária, muito interessante (GRAMSCI, 2004a, p.387).

Segundo nosso autor, a partir do momento em que o operariado conseguir sua emancipação, conseguirá também emancipar as camadas oprimidas pelo capitalismo italiano. Portanto, o proletariado turinense tornou-se o dirigente das massas operárias italianas, “(o ideal para todo operário italiano é poder trabalhar em Turim)" (idem), de todos os cantos da Itália as massas operárias manifestavam seu sentimento de solidariedade com os movimentos dos trabalhadores das fábricas turinense, "eles viam nesta cidade o centro, a capital da revolução comunista, a Petrogrado da revolução proletária italiana” (ibidem).

A produção industrial turinense era bem sistematizada e homogênea, sendo que a indústria metalúrgica ocupava o primeiro lugar com cerca de 50 mil operários e 10 mil empregados e técnicos. A fábrica da FIAT, por exemplo, compreendia cerca de 35 mil trabalhadores, entre eles 16 mil operários trabalhavam diretamente com a construção de automóveis com sistemas bem aperfeiçoados e modernos. Como podemos perceber, a maioria desses trabalhadores era formada por operários qualificados e técnicos, porém não possuíam a mentalidade da pequena burguesia de países bem industrializados como a Inglaterra (Gramsci, 2004a).

Salvo as guardadas proporções, todo movimento operário representava a ação das massas trabalhadoras sobre um caráter político e revolucionário, a indústria automobilística assumia o primeiro lugar no sistema de produção, subordinava a si os ramos da madeira e de borracha, com essa esfera de grande centralização de produção em Turim, a cidade possuía uma única organização sindical importante, a Câmara do Trabalho com aproximadamente 90 mil filiados (Gramsci, 2004a).

"O movimento comunista dispõe das seguintes organizações de luta: a seção do Partido, com 1.500 filiados; 28 núcleos com 10 mil sócios; 23 organizações juvenis, com 10 mil inscritos” (idem, p.386). Esse conglomerado de pessoas mobilizadas pela luta de classes e pela revolução proletária, cada empresa 
possui seu grupo comunista, cada grupo se une em grupos de bairros, sendo direcionados sobre a matriz de uma organização central, que têm ao seu redor todo o movimento da massa operária.

Uma greve em abril de 1920 realizada em Turim, foi um exemplo da força que continha toda essa organização e centralização das massas operárias na cidade, “a greve geral dos últimos dez dias espalhou-se por todo o Piemonte, mobilizando cerca de meio milhão de operários industriais e agrícolas e envolvendo cerca de 4 milhões de pessoas" (GRAMSCI, 2004a, p.384). Porém, as ações operárias foram sufocadas por todo o aparato do Estado burguês italiano, nem o Partido Socialista nem a Confederação Geral do Trabalho ofereceram ajuda para os trabalhadores em combate. Mas isso deixou algo muito bem esclarecido para todos, Turim é certamente o centro industrial italiano e pode-se favorecer a esperança da revolução, iniciando-a por lá.

Com essas aspirações, a propaganda do conselho de fábrica foi sendo difundido e bem visto pelas massas, de acordo com Gramsci (2004a) foram constituídos conselhos em todas as fábricas e estabelecimentos metalúrgicos, os comunistas conquistaram a maioria nos sindicatos, o princípio dos conselhos de fábricas foi aprovado pela maioria dos sindicatos pertencentes à Câmara do Trabalho.

A organização dos conselhos de fábrica baseia-se nos seguintes princípios: em toda fábrica, em toda oficina é formado um organismo com base na representação (e não no antigo sistema burocrático), que põe em prática a força do proletariado, luta contra a ordem capitalista ou exerce o controle sobre a produção, educando toda a massa operária para a luta revolucionária e para a criação do Estado operário. O conselho de fábrica deve ser formado segundo o princípio da organização por indústria; deve representar, para a classe operária, o modelo da sociedade comunista, à qual se chegará através da ditadura do proletariado; nesta sociedade, não mais haverá divisões de classe, e todas as relações sociais serão reguladas segundo as exigências técnicas da produção e da organização correspondente, não sendo subordinadas a um poder estatal organizado. A classe operária deve compreender toda a beleza e nobreza do ideal pelo qual luta e se sacrifica; deve entender que, para alcançar este ideal, é necessário atravessar algumas etapas; deve reconhecer a necessidade da disciplina revolucionária e da ditadura (idem, p.392-393).

Com a conscientização e mobilização dos operários, devido a grande força dos conselhos de fábricas, até as greves que antes eram impulsivas e fortuitas, se tornaram mais organizadas e verdadeiramente expressão consciente das massas revolucionárias. Após uma agressão feita por alguns nacionalistas aos deputados socialistas que se manifestaram contra o monarquismo no parlamento, eclodiu um enorme ato de greve espontâneo que por dois dias envolveu as grandes cidades do norte italiano, os conselhos de fábricas sendo os organizadores desse ato tiveram grande excito, e um exército proletário foi em direção ao centro de Turim, dando exemplo do seu poder político e militante (Gramsci, 2004a).

Porém as fortes prerrogativas operárias comunistas começaram a ser barradas por uma disputa dentro da própria luta pela organização dos conselhos de fábrica, os socialistas colocavam entrave até mesmo na elaboração do próprio conceito de conselho de fábrica. Nas entrelinhas de seus discursos estava presente o desejo de evitar a participação direta das massas nas lutas de classes revolucionária, conservando o desejo de manter a tutelo dos sindicatos comandando as massas. O movimento turinense foi ridicularizado e mantido à margem das conversações políticas que representariam a classe trabalhadora. Sob as investidas do Partido Socialista e das organizações sindicais contra os conselhos, os capitalistas se encorajaram e armou 
todo seu estratagema com o apoio do Estado burguês para sufocar os conselhos e seus operários, de acordo com Gramsci (2004a).

Nesse âmbito de disputa e controle, entre a burguesia e o proletariado para ser a classe dirigente das massas, os conselhos de fábrica eram muito importante, pois isso precisa de organização e mobilização; "Esta forma de organização só pode ser o conselho de fábrica. Esta deve ter como resultado a constituição de um conselho nacional da classe operária... (idem, p.39)".

Os conselhos de fábrica que já eram visto como um dos pontos principais da tomada de poder pelos operários, naquele momento de disputa ganhou mais relevância ainda. Gramsci (2004b) reforça que os conselhos representavam a única forma de organização do proletariado industrial, já que os sindicatos se renderam aos capitalistas e suas burocracias. "Por isso, os conselhos são os mais interessados no controle e na nacionalização da indústria (p.44)".

Percebe-se então nessa perspectiva de tomada de poder pela classe trabalhadora, a importância dos conselhos de fábrica nessa premissa e principalmente sua força de organização e mobilização dos operários. Gramsci sempre foi muito atuante e fazia questão de ressaltar o valor dos conselhos, sendo um dos idealizadores do jornal dos operários, L’Ordine Nuovo, nunca deixara abalar seus propósitos comunistas, um busca de um Estado italiano onde os trabalhadores comandassem o modo de produção.

\section{Considerações finais}

O calor de uma mobilização intensa, a ocupação das fábricas, o enfrentamento ao capital, são características fundamentais do designado biênio vermelho e que principalmente teve como personagem um dos maiores ativistas políticos da história italiana e do mundo - Antônio Gramsci. O entusiasmo deste intelectual orgânico foi essencial para os acontecimentos revolucionários nesses dois anos de efervescência política na Itália.

Essa intensa militância de Gramsci foi sendo constituído no decorrer de sua vida, podendo ela ser iniciada pelo simples fato de nascer em um local oprimido geopoliticamente, seja pelas influências familiares, e/ou principalmente por ter contato direto e ter se encantado com os movimentos operários no momento de sua graduação e profissionalização em Turim. Sua vida de militância em paralelo com a carreira jornalística apresentou ao contexto político, um jovem sardo viril, motivado e capaz de levar até as ultimas consequências seus desejos revolucionários.

Ainda para ele, a filosofia não é condição específica de cientistas especializados ou de filósofos conceituados. Filosofia para Gramsci (1999) é condição humana (capacidade de interpretar o real). Todos os homens são filósofos, podem e devem - mesmo que inconscientemente - participar da constituição histórica da humanidade, sendo esta uma forma de convocar e aguçar nos trabalhadores a vontade de participação na vida política. Filosofia para Gramsci é ação política, portanto, todos aqueles que constituem a classe trabalhadora - camponeses do sul e operários do norte - deveriam estar unidos em prol de um só objetivo, organizar a revolução comunista e instaurar o Estado proletário. 
Finalizando este estudo, fica em destaque uma passagem em que Gramsci escreve a sua mãe, confirmando seu ímpeto revolucionário e reafirmando seu amor a militância política a favor da revolução. No cárcere em 1926 em Roma - primeiro ano de sua prisão - escreveu a sua mãe, pedindo perdão, pedindo para que seja forte assim como ele é, e principalmente dizendo, "estou tranquilo e sereno. Moralmente estava preparado para tudo" (Gramsci, 2011, p.), ou seja, estar preparado moralmente para tudo pode significar que sabia muito bem o que estava fazendo em toda sua vida militante e, sobretudo, orgulho de fazer o que fez.

\section{Referências}

FIORI, Giuseppe. (2015). Antonio Gramsci - Vida de un revolucionario. Tradussción de Jordi Solé Tura. Madrid: Capitán Swing Libros, S.L.

GRAMSCI, A. (1999). Cadernos do cárcere. Volume 1. Edição e Tradução de Carlos Nelson Coutinho; Coedição de Luiz Sérgio Henriques e Marco Aurélio Nogueira. Rio de Janeiro: Editora Civilização Brasileira. Cartas do cárcere. Estaleiro Editora. Versão Galega. 2011.

. (2004a). Escritos Políticos. Volume 1. Organização e tradução de Carlos Nelson Coutinho. Rio de Janeiro: Editora Civilização Brasileira.

(2004b). Escritos Politicos. Volume 2. Organização e tradução de Carlos Nelson Coutinho. Rio de Janeiro: Editora Civilização Brasileira.

\section{Notas}

${ }^{1}$ Mestrado em Educação pela FE-UFG, bolsista pela CAPES. Especialização em Psicologia dos Processos Educativos pela FEUFG. Especialização em Sociologia e Docência Universitária pela Instituto Aphonsiano de Ensino Superior. Graduado em Educação Física pela Faculdade União de Goyazes. ORCID: http://orcid.org/0000-0003-0751-1682 Email: wplima9@gmail.com

2 Companheiro de militância e parceiro no jornal Avanti! de Turim. 